\title{
Phenylalanine Ammonia-Lyase and Source-Flow-Sink Related Attributes in Rice Genotypes Subjected to High Night Temperatures
}

\author{
Diogo S. Moura ${ }^{1}$, Giovani G. Brito ${ }^{2}$, Ângela D. Campos ${ }^{2}$, Ítalo L. Moraes ${ }^{1}$, Paulo R. R. Fagundes ${ }^{2}$ \\ \& Sidnei Deuner ${ }^{1}$ \\ ${ }^{1}$ Federal University of Pelotas, Campus Capão do Leão, RS, Brazil \\ ${ }^{2}$ EMBRAPA Temperate Climate, Brazilian Agricultural Research Corporation, Pelotas, RS, Brazil \\ Correspondence: Giovani G. Brito, EMBRAPA Temperate Climate, Brazilian Agricultural Research Corporation, \\ Pelotas, RS, Brazil. E-mail: giovani.brito@embrapa.br
}

Received: September 27, 2017

Accepted: October 31, 2017

Online Published: November 15, 2017

doi:10.5539/jas.v9n12p268

URL: https://doi.org/10.5539/jas.v9n12p268

\begin{abstract}
Phenylalanine ammonia-lyase (PAL) which is considered to be one of the main lines of cell acclimation against stress in plants, non-structural carbohydrates (NSC) accumulation and chlorophyll fluorescence parameters were quantified in two rice genotypes as a function of two temperature regimes: $22 / 30{ }^{\circ} \mathrm{C}$ (control) and $28 / 30{ }^{\circ} \mathrm{C}$ night/day (high night temperatures - HNT), imposed from heading to milk stage. The rice cultivars chosen were Nagina22 (N22) and BRS Querência (BRS-Quer), which are genotypes tolerant and sensitive to high temperatures, respectively. BRS-Quer genotype highlighted more sensitive responses maintaining higher PAL and peroxidase levels on seventh and twenty-first days after stress imposing. On the other hand, this genotype showed levels of fructose, glucose and sucrose decreasingly across stress period whether compared to N22. Both genotypes showed similarity for most of the chlorophyll fluorescence parameters. However, the photosynthesis induction curve highlighted that HNT caused decreases in some photochemical quenching of fluorescence as well as increases of non-phochemical quenching, affecting more prominently BRS-Quer genotype. N22 maintained unaltered the spikelet sterility and 1000-grain weight across temperature regimes showing a consistent trend with its stem NSC accumulation during stress period. The higher availability of soluble sugars shown by $\mathrm{N} 22$ at the end of stress period could be unloaded in spikelet formation and grain fillings contributing in their lower sterility rate and greater 1000-grain weight stability across the environments. These results indicate that selecting genotypes with higher capacity to stem NSC translocation beyond accumulation at HNT could lead to more grain yield stability in future climate scenarios.
\end{abstract}

Keywords: Oryza sativa L., night heat stress, photosynthesis, chlorophyll fluorescence, climate change

\section{Introduction}

Abiotic and biotic stresses represent the major constraints that result in agricultural losses on the global scale and projected climate changes could increase their negative effects in the future (Brito et al., 2010, 2011, 2016; Diola et al., 2011, 2013; Weber et al., 2014; Guimarães et al., 2017). Recently, reports are highlighting via climate models predict an increasing frequency and intensity of heat waves and high temperature events throughout current century (IPCC, 2013; Becklin et al., 2016). Beyond of the predict impact of these extreme event on global population, remain unclear its influence on plant species distributions, productivity, carbon balance and physiological impact versus plant resilience capacity. In this sense, efforts and new strategies are imperative in the breeding program aiming to obtain new plant ideotypes for new climate scenarios.

Rice (Oryza sativa L.) is one of the most relevant staple food for more than half of the world's population (Fan et al., 2016). The grain rice production must be increased by $70 \%$ until 2050 to supply the growing demand for food, take into account the growth population and economic development (Godfray et al., 2010). Additionally, there is a consensus that in the future the high temperatures will become a bottleneck for crop yield and its stability. In this way, projected climate changes could increase its negative effects in the future (Tian et al., 2015; Fan et al., 2016). Although projected impact of climate change on crop yield has been extensively published in the last decade, yet are unexpressive studies that highlight the role of increase in nighttime temperatures on rice physiological response and, consequently, changes in the rice yield performance. 
There were extensively reported that in the future, increases in $\mathrm{CO}_{2}$ concentration could lead to a better performance to photosynthesis and increases in carbohydrate metabolism enzymatic activity in the source (leaf) in the absence of other bottlenecks. In this way, higher non-structural carbohydrates (NSC) could be accumulated in the sink (grains) among crop plants. It could result in more cumulative product of increased tillers, panicles, spikelet per panicle and proportion of filled spikelets, besides to enhanced 1000-grain weight (Shimono et al., 2009; Zhu et al., 2014). On the other hand, the negative effects from heat stress, especially during initial reproductive phase could lead to decrease the rice grain yield and its components, by increase the spikelets sterility rate, shorter grain filling period and disrupt the sink activity. Take into account the faster leaf senescence associated to accelerate photosynthesis reductions, decreasing in sucrose-starch conversion via enzymatic activity, could reduce the grain yield and the quality (Bahuguna et al., 2017; Chaturvedi et al., 2017; You et al., 2017).

Considering that starch represents $80-90 \%$ of final rice grain weight, the events involving since grain filling and final yield are associated to assimilates supplied by current photosynthesis and stem NSC remobilization capacity (Yoshida, 1981). During the vegetative phase and until heading, carbon assimilates are partially and temporally stored in stems and leaf sheaths of plant's rice as NSC which are sinked for all events involving since reproductive organ formation until grain development and maturation phase (Morita \& Nakano, 2011; Zhang et al., 2016). For rice, there are studies showing that the stem NSC contribution to grain yield must reach 28\% (Yoshida, 1981; Pan et al., 2011). Besides, there are indications that stem NSC at full heading stage of rice can increase the grain ripening ratio in those plants submitted to heat stress, increasing its grain yield stability (Morita \& Nakano, 2011). For those plants submitted to drought at pre-anthesis stem NSC accumulation have highlighted its potential to buffer grain-filling in both wheat and rice (Yang et al., 2001; Saint Pierre et al., 2010) and also has been associated to tolerance to long-term partial submergence in rice (Kato et al., 2014). In this way, different strategies should be used by plants to respond to environment oscillations including those related to phenylpropanoids pathways.

Phenylalanine ammonia-lyase (PAL) catalyzes the first step in the phenylpropanoid pathway, leading L-phenylalanine undergoes deamination to yield ammonia and trans-cinnamate (Dixon et al., 2002). Thus, flavonoids, isoflavonoids, anthocyanins, phytoalexins, anthocyanins and lignins biosynthesis are dependent of PAL activity (Pascual et al., 2016; Dempsey \& Klessig, 2017). These compounds are involved in different events, which include plant defense against pathogens and predators, in the protection from UV irradiation and low temperatures responses (Dixon \& Paiva, 1995; MacDonald \& D'Cunha, 2007). In this way, the detection of different PAL activity in heat stress contrasting genotypes when submitted to high night temperature could lead to a new efforts aiming development/establishment of PAL activity as a biochemical marker suitable for physiological breeding phenotype aiming to obtain rice cultivars more tolerant to future climate scenarios.

Although enormous quantities of studies involving projected impacts of climate change on crop yield has been extensively published in the last decade, yet there are gaps underling the rice physiological responses when plants are submitted to high night temperatures. Thus, this study evaluated the effects of high night temperature on PAL activity which is considered to be one of the main lines of cell acclimation against stress in plants, on NSC accumulation and chlorophyll fluorescence parameters in contrasting rice genotypes as a function of two temperature regimes.

\section{Material and Methods}

\subsection{Plant Materials}

Two rice genotypes, a heat-tolerant Nagina22 (N22) and heat-sensitive BRS Querência (BRS-Quer) based in our previous trials, compounded our genetic plant materials for this study. These genotypes have showed similar cycle but significant differences for that grain weight and panicle size grown under field conditions.

\subsection{Growth Conditions and Treatments}

Rice plants were grown in pots $(3.0 \mathrm{~kg}$ soil) and maintained within a greenhouse from sowing until plant heading stage (Figure 1A). After, half of plants from each genotype were taken to two growth chambers (Figure 1B) aiming to impose pre-defined treatments. In the date, in order to ensure that the same sample was ever used for physiological non-destructive analysis, the youngest and expanded leaf was labeled. 


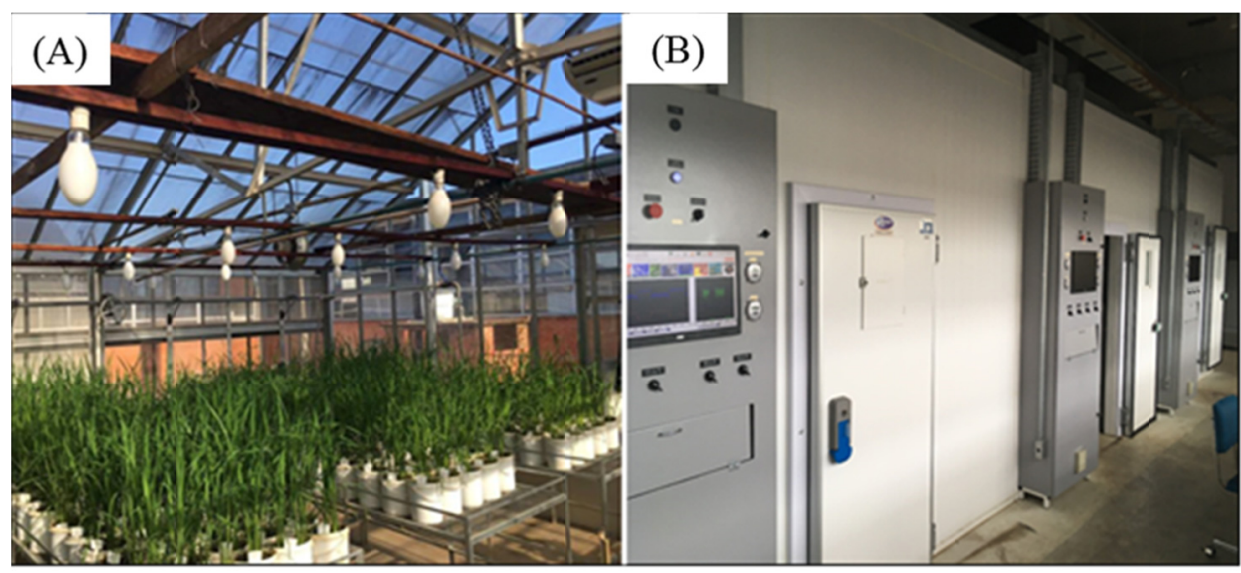

Figure 1. Installations as facilities used for trials: greenhouse (A) and growth chambers (B)

The growth chambers were programmed to maintain a temperature according to predefined temperatures regimes; a growth chamber was programmed to maintain them at $22.0 / 30{ }^{\circ} \mathrm{C} \pm 0.5^{\circ} \mathrm{C}$ (night/day) for control whereas for heat stress treatment, temperatures were $28.0 / 30{ }^{\circ} \mathrm{C} \pm 0.5^{\circ} \mathrm{C}$; being the dark period $(10 \mathrm{~h})$, for the light period $(14 \mathrm{~h})$ at $500 \mu \mathrm{mol} \mathrm{m} \mathrm{m}^{-2} \mathrm{~s}^{-1}$ approximately. Four biological replicates of each treatment were carryout considering the required time for chlorophyll fluorescence analyzes. These procedures were conducted on seventh (at heading) and twenty-first days (milk stage) during the stress period. For biochemical analyzes, plant submitted to control and stress conditions were also sampled at these two time-points: on seventh days after heading $\left(\mathrm{R}_{3}\right)$ and at milk stage $\left(\mathrm{R}_{5} / \mathrm{R}_{6}\right)$ (Counce et al., 2000).

\subsection{Enzymatic Determinations}

As before described, enzymatic analyzes were conducted on seventh (at heading) and twenty-first (at milk stage) days after stress imposing. Were sampled flag leaves from three plants and tissue weighted and immediately frozen in dry ice and subsequently stored at $-30{ }^{\circ} \mathrm{C}$ until analyzes procedures. Peroxidase activity was quantified as described by (Campos et al., 2003). Briefly, leaf tissues $(0.5 \mathrm{~g})$ were homogenized with a mortar and pestle at $4{ }^{\circ} \mathrm{C}$ in $20 \mathrm{~mL}$ of extraction buffer [0.05M phosphate buffer (pH 7.0) and $1.0 \mathrm{mg}$ of pholynilpirolidon (PVP)-10. The homogenate was filtered and then centrifuged at $4000 \mathrm{~g}$ for $20 \mathrm{~min}$ at $4{ }^{\circ} \mathrm{C}$ and precipitated residues were discarded. Subsequently, the supernatant was used in the determinations of peroxidase activity according to method described by Campos and co-workers (Campos et al., 2003).

PAL activity was measured as described previously by (Hyodo \& Yang, 1971; Hyodo et al., 1978) and modified by (Campos et al., 2003). Briefly, extracts of leaves tissues $(0.5 \mathrm{~g})$ were homo-genized with a mortar and pestle in $6 \mathrm{~mL}$ of extraction buffer [50 $\mathrm{mM}$ Tris-HCl buffer ( $\mathrm{pH} 8.8), 15 \mathrm{mM} \mathrm{b}$-mercaptoethanol, $5 \mathrm{mM}$ EDTA, $5 \mathrm{mM}$ ascorbic acid, $10 \mathrm{mM}$ leupeptin, $1 \mathrm{mM}$ phenylmethylsulfonyl fluride (PMSF) and $0.15 \% \mathrm{w} / \mathrm{v} \mathrm{PVP]}$. The homogenate was filtered through four layers of cheesecloth and then centrifuged at $12000 \mathrm{~g}$ for $20 \mathrm{~min}$ at $4{ }^{\circ} \mathrm{C}$. Protein concentration in the extracts was determined by the Lowry method (Lowry et al., 1951).

\subsection{Chlorophyll Fluorescence Measurements}

On seventh (at heading) and twenty-first (at milk stage) days after stress imposing some chlorophyll fluorescence parameters were quantified. For all treatments, measurements were started on youngest expanded leaf on four different plants $(n=4)$. The leaves used for were tagged to allow making these analyses using always the same leaves. The mid to distal portion of each leaf blade was inserted in the leaf chamber for measurements. Subsequently, analyzes were done using a PAM-2500 fluorometer (Walz Heinz GmbH, Effeltrich, Germany). Before measurements, plants were dark-adapted overnight within each grow chamber. The basal fluorescence $\left(\mathrm{F}_{0}\right)$ at open photosystem II (PSII) centers was determined by measurement light (less than $30 \mu \mathrm{mol} \mathrm{m} \mathrm{s}^{-2}$ ), whereas the maximum fluorescence $\left(\mathrm{F}_{\mathrm{m}}\right)$ at closed or in a reduced state of PSII centers was evaluated after a application of a $0.8 \mathrm{~s}$ pulse of saturating light $\left(7000 \mu \mathrm{mol} \mathrm{m}^{-2} \mathrm{~s}^{-1}\right)$. The maximum quantum efficiency of PSII $\left(\mathrm{F}_{\mathrm{v}} / \mathrm{F}_{\mathrm{m}}\right)$ was defined as $\left(\mathrm{F}_{\mathrm{m}}-\mathrm{F}_{0}\right) / \mathrm{F}_{\mathrm{m}}$. Induction curves were done by pulse of saturating light applied at each 20 seconds until steady-state reached. During measurements the actinic light (red light) was turn on to quantify the steady-state of chlorophyll fluorescence $\left(\mathrm{F}_{\mathrm{s}}\right)$. Plants in the light-adapted state, $\mathrm{F}_{\mathrm{m}}{ }_{\mathrm{m}}$ was analyzed via application of saturating pulse, whereas $\mathrm{F}_{0}$ ' was evaluated by switching off the actinic light for $2 \mathrm{~s}$ after the saturating pulse and turn on 
the far-red light. Non-photochemical quenching (NPQ) quantified by ratio $F_{m} / F_{m}{ }_{m}-1$; effective quantum efficiency of PSII (Y(II)) defined as $\left(\mathrm{F}_{\mathrm{m}}{ }_{\mathrm{m}}-\mathrm{F}_{\mathrm{s}}\right) / \mathrm{F}_{\mathrm{m}}$; photochemical quenching $(\mathrm{qP})$ defined as $1-\left(\mathrm{F}_{\mathrm{s}}-\mathrm{F}^{\prime}{ }_{0}\right) /\left(\mathrm{F}_{\mathrm{m}}{ }_{\mathrm{m}}-\mathrm{F}^{\prime}\right)$ and electron transfer rate (ETR) defined as PAR.ETR-factor.P $\mathrm{PS}_{\mathrm{PS}} / \mathrm{P}_{\mathrm{PPS}} . \mathrm{Y}(\mathrm{II})$ (Baker, 2008).

\subsection{Non-Structural Carbohydrates Determination (NSC)}

Plants from both genotypes and temperature regime were cut in the basal portion of the culm between 09:00 and 10:00 $\mathrm{h}$ at seventh day after heading and at milk stage aiming quantify its NSC (total soluble sugar and starch in glucose). Five plants from each treatment were sampled for biochemical analyzes; this plants were separated into leaves, stem and panicles and immediately weighted and dried at $60{ }^{\circ} \mathrm{C}$ and subsequently stored. After, these samples were grounded (50 mesh); the extraction done in ethanol $80 \%$, in water bath at $95{ }^{\circ} \mathrm{C}$ during 10 minutes, centrifuged at 2,500 rpm by five minutes. Total soluble sugar (TSS) determinations were carry out using supernatant extract and the starch was quantified in the residue remaining after soluble sugars extraction; the total sugars were extracted using phenol-acid and the starch in residue remaining, which was dried and further extracted using enzymatic hydrolyze and subsequently quantified via PGO enzyme addition (Chow \& Landhausser, 2004). Glucose, fructose and sucrose determinations were carry out via gas chromatography (Streeter \& Strimbu, 1998); the derivatization was done using HMKS:TMCS (3:1).

\subsection{Yield Components Measurements}

After the stress period, all genotypes were taken back to the greenhouse where were maintained until physiological maturity. After, some yield components were quantified harvesting each plant separately; the grain weight was adjusted to $14 \%$ moisture content; were quantified the panicle grain number, percentage of spikelet sterility, 10-panicle weight and 1000-grain weight.

\subsection{Statistical Procedures}

For biochemical and yield components, data were analyzed using a two-way ANOVA and when significant interaction was detected, unfold statistical procedures were done aiming to quantify the effects of each genetic background within each temperature regime (control and under heat stress) (SigmaPlot 13.0 - Systat Software San Jose). Subsequently, the Least Significant Difference (LSD) among the means was statistically analyzed using Student-Newman-Keuls test $(\mathrm{p}<0.05)$. For chlorophyll fluorescence parameters, curves were constructed considering its standard errors for each measured point.

\section{Results}

Analysis of genotypes versus temperature regimes of the PAL and peroxidase enzymes detected significant statistical interaction $(\mathrm{P}<0.001)$ on seventh and twenty-first days after stress imposing. Both genotypes submitted to temperature regimes not shown significant differences in their peroxidase levels at control condition, except when submitted to HNT on seventy and twenty-first days after heading phase when BRS-Quer showed an increase of $80 \%$ and $21 \%$ for this enzyme, respectively (Figure 2). For PAL enzyme, N22 showed higher level activity (93\% higher than BRS-Quer) even when maintained under control conditions.

Additionally, its activities levels were unaltered on the seventh and twenty-first days after stress imposing, suggesting some constitutive traits for N22 PAL stability across evaluated environment. On the other hand, there were an increase of $270 \%$ and $161 \%$ in PAL activity on seventh and twenty-first days for BRS-Quer, respectively. 

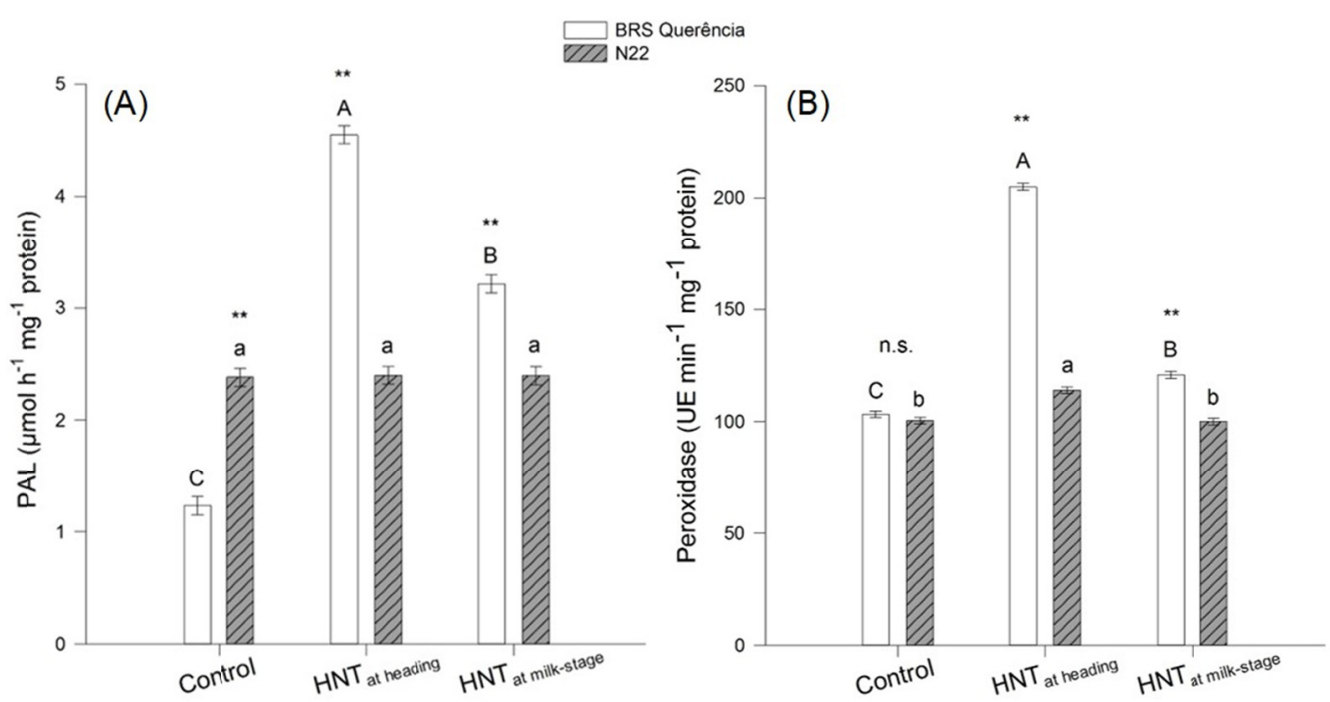

Figure 2. Phenylalanine ammonia-lyase - PAL (A) and peroxidase activity (B) in rice genotypes submitted to different temperatures regime

Note. For white columns (BRS Querência - BRS-Quer) and cross gray columns (Nagina22 - N22) followed by the same capital letter and the same lowercase letter, respectively, are not significantly different at the $p<0.05$ level by the Student-Newman-Keuls test. The symbols ** and n.s. mean significant difference at the $\mathrm{p}<0.01$ and non-significant level, respectively, for a given night temperature condition among the contrasting genotypes.

At milk stage, chlorophyll fluorescence analyzes as a probe for photosynthesis performance were used. Chlorophyll fluorescence can provide information about the functional state of the thylakoid membranes into the chloroplasts when plants are submitted to biotic or abiotic stresses. Both genotypes were similar for some rapid curve induction parameters as such Y(II) (Figure 3) and qP (Figure 4), which estimates the fraction of absorbed quanta used for PSII photochemistry and the fraction of open PSII reaction centers, respectively independently of temperature regimes and time evaluations. At control condition, N22 showed a higher (21.5\%) ETR tendency (Figure 5), whereas a lower (40\%) NPQ (Figure 6); both achieving similar performance on the twenty-first day after stress imposing. 

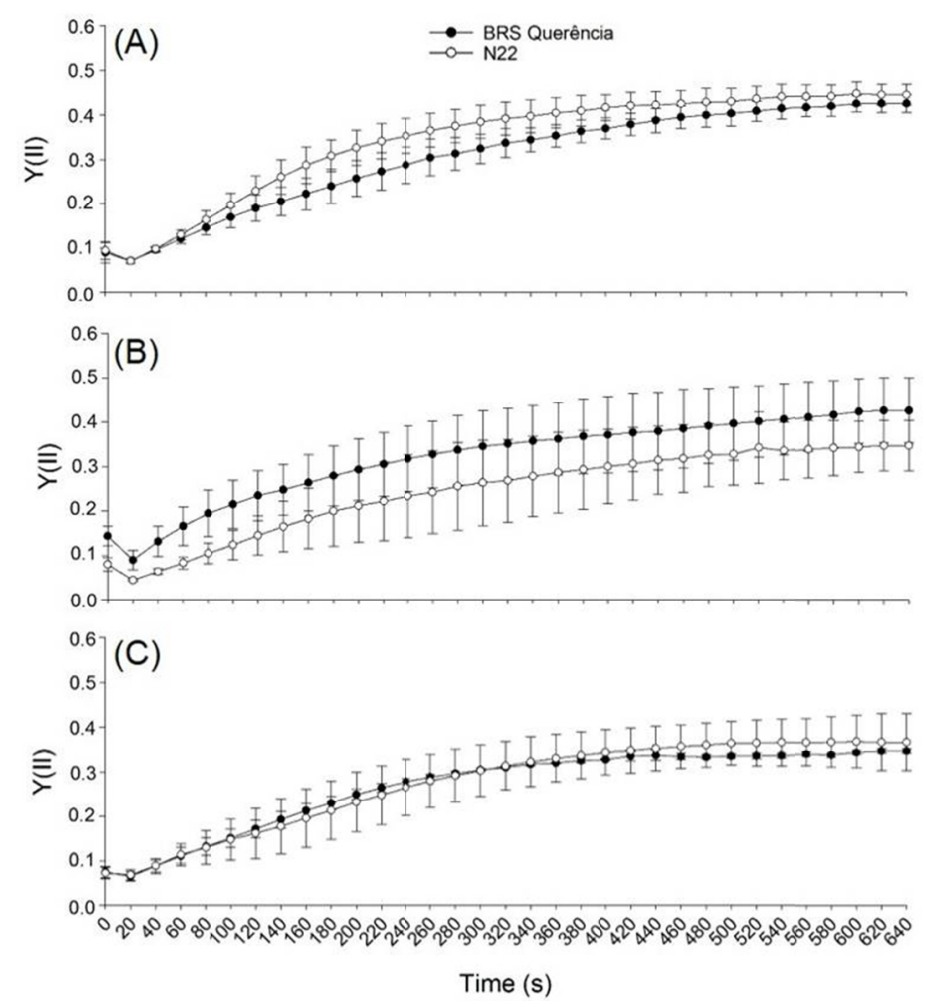

Figure 3. Effective photochemical quantum yield (Y(II)) at control condition (A) and on seventh (B) and twenty-first days after the high night temperatures imposing $(C)$ in rice genotypes
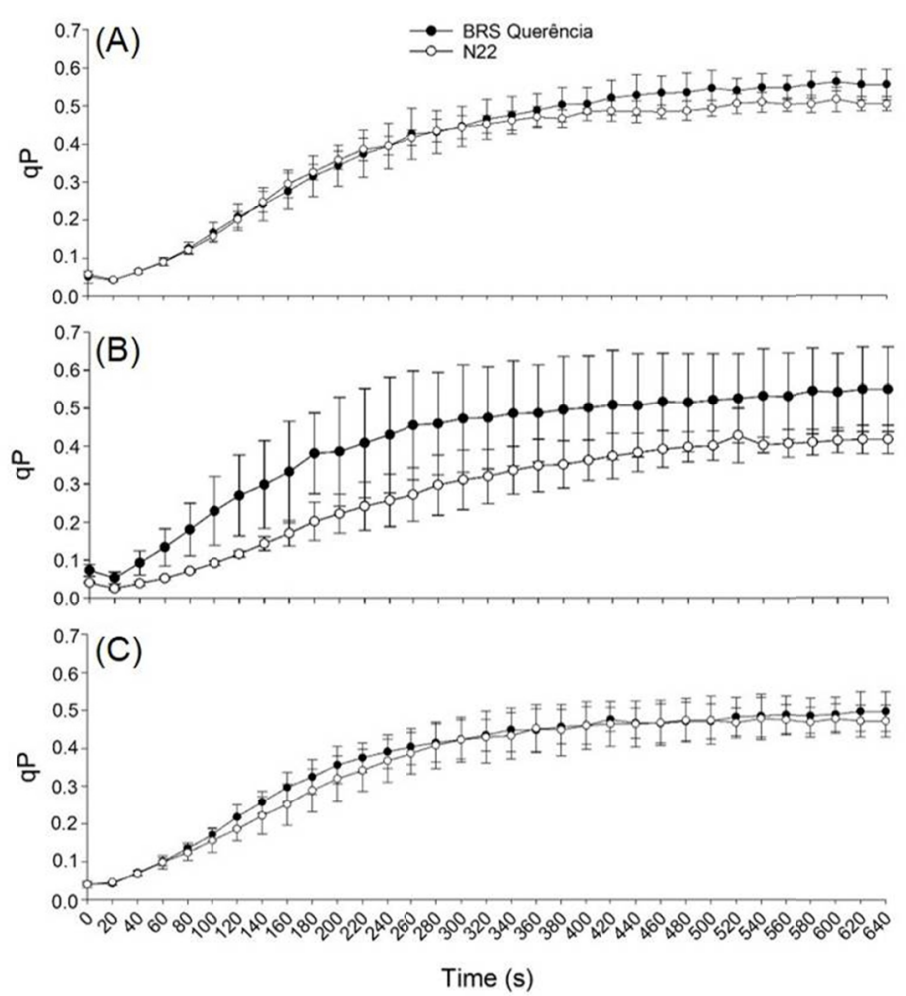

Figure 4. Photochemical fluorescent quenching (qP) at control condition (A) and on seventh (B) and twenty-first days after the high night temperatures imposing $(\mathrm{C})$ in rice genotypes 

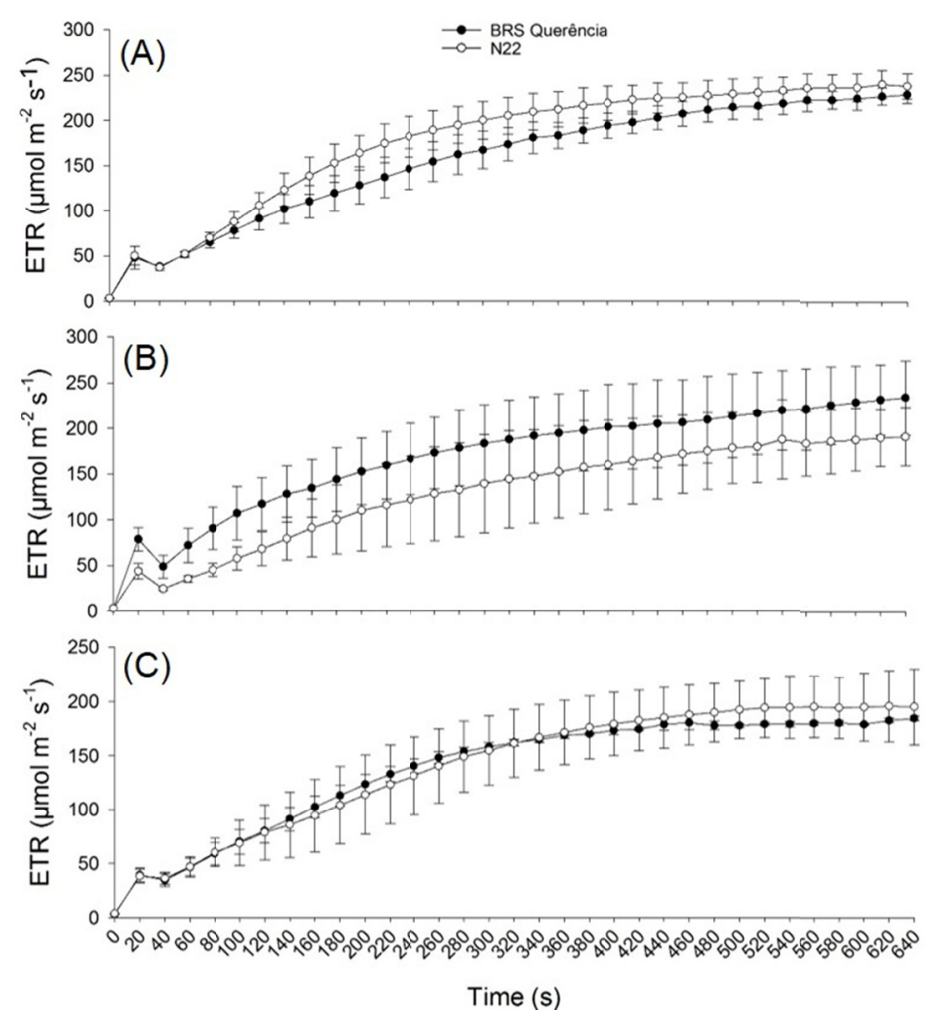

Figure 5. Relative electron transfer rate (ETR) at control condition (A) and on seventh (B) and twenty-first days after the high night temperatures imposing $(C)$ in rice genotypes
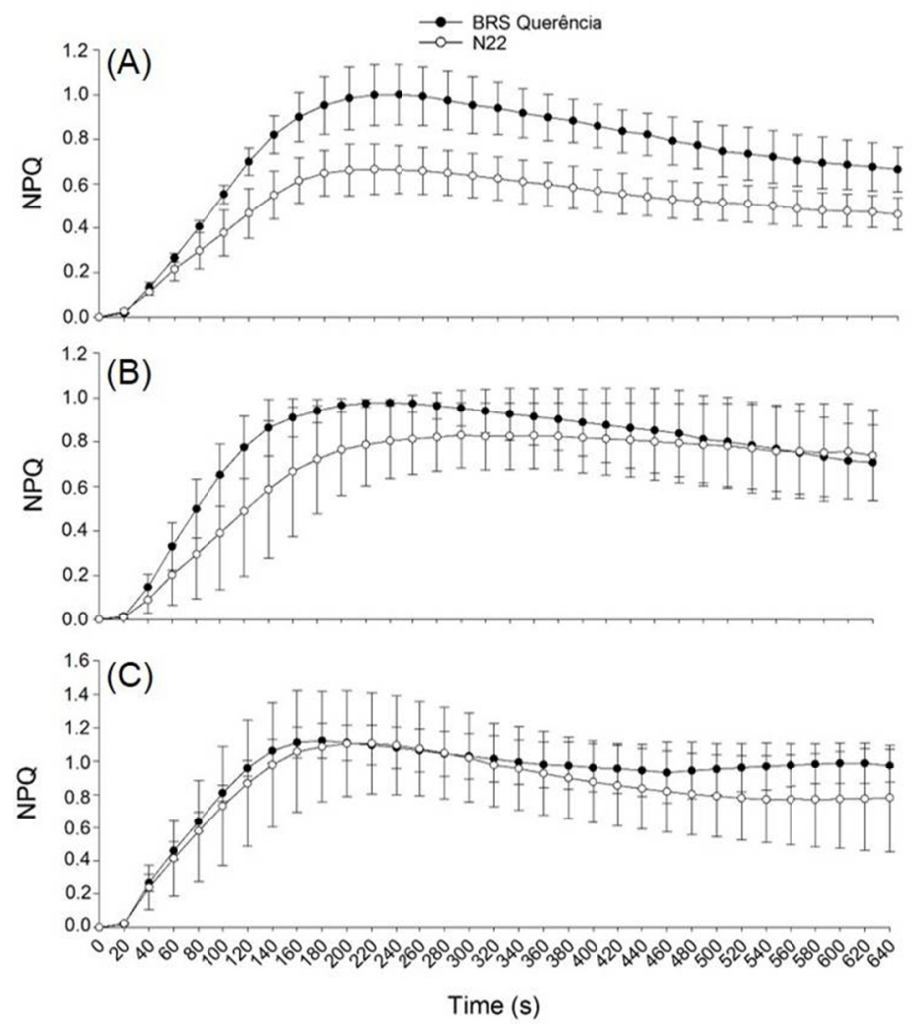

Figure 6. Non-photochemical quenching (NPQ) at control condition (A) and on seventh (B) and twenty-first days after the high night temperatures imposing $(\mathrm{C})$ in rice genotypes 
For TSS on seventh and twenty-first days and for starch content on twenty-first there were a significant temperature regimes $x$ genotypes interaction $(\mathrm{P}<0.001)$ (Figure 7). BRS-Quer genotype showed the highest starch values independently of imposed treatments, whereas, N22 showed the highest TSS on control treatment and on twenty-first day after HNT imposing. There were tendencies of decreases of TSS across environment regime and stress duration for BRS-Quer. Beyond to its greater capacity to maintain higher TSS level at control condition, N22 showed also the higher recovery capacity for TSS values on twenty-first day after stress imposing. In same way, the starch content for BRS-Quer genotype were maintained higher (563\%) when compared to N22 on seventh day. However, starch values shown by N22 were always lower until seventy day with a tendency to a small recovery on twenty-first day after stress imposing. For glucose and sucrose, N22 showed a tendency to decrease its NSC levels with greater recovery capacity at the end of stress period (Figure 8).
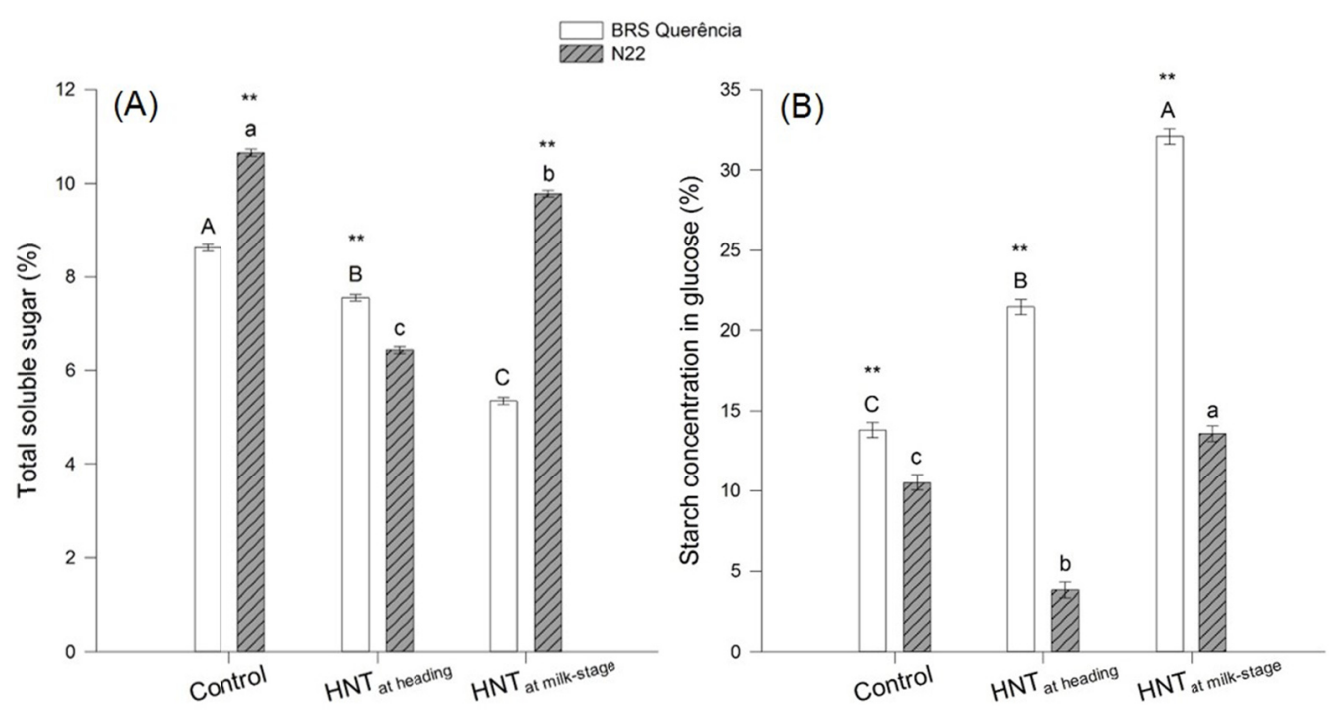

Figure 7. Total soluble sugar - TSS (A) and starch concentration in glucose (B) in rice genotypes submitted to different temperatures regime

Note. For white columns (BRS Querência - BRS-Quer) and cross gray columns (Nagina22 - N22) followed by the same capital letter and the same lowercase letter, respectively, are not significantly different at the $p<0.05$ level by the Student-Newman-Keuls test. The symbols $* *$ and n.s. means significant difference at the $\mathrm{p}<0.01$ and non-significant level, respectively, for a given treatment condition among the contrasting genotypes.

At milk stage, were also confirmed significant HNT $\times$ genotypes interaction $(\mathrm{P}<0.001)$ for TSS and starch (Figure 7). The TSS content was maintained higher in N22 if compared to BRS-Quer genotype independently of imposed treatments. Besides, N22 showed a lower decrease ratio in TSS from control to HNT conditions (8\%) whereas a more abrupt reduction (38\%) was highlighted for BRS-Quer at this phase. In other way, higher levels of starch were maintained in the BRS-Quer in both temperature regimes; additionally, there were a stronger starch accumulation (increase of 132\%) from control to HNT for this genotype whether compared to N22. At milk stage, there were an increase of 55\% for fructose, $350 \%$ for glucose and $266 \%$ for sucrose in N22 when compared to BRS-Quer genotype. Besides, both genotypes maintained unaltered its fructose and glucose levels from control to HNT regimes, except for sucrose content where were highlighted significant decreases for both evaluated genotypes (Figure 8). 

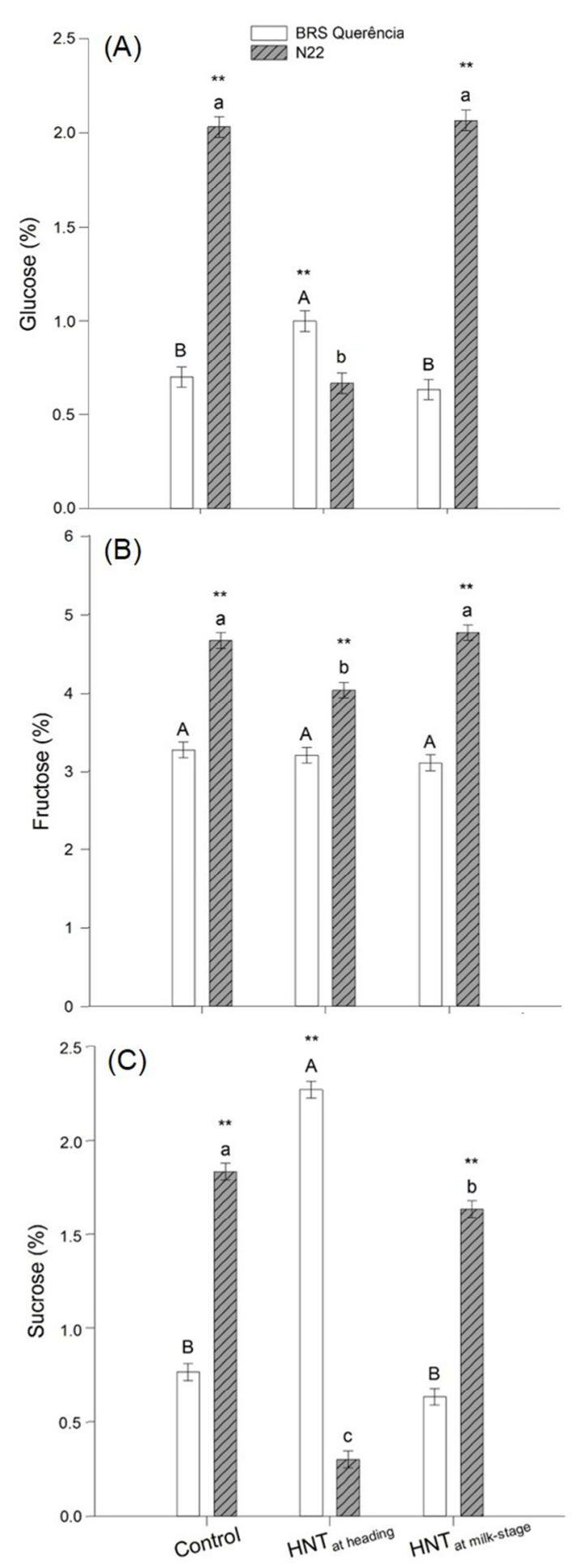

Figure 8. Glucose (A), fructose (B) and sucrose (A) in rice genotypes submitted to different temperatures regime Note. For white columns (BRS Querência - BRS-Quer) and cross gray columns (Nagina22 - N22) followed by the same capital letter and the same lowercase letter, respectively, are not significantly different at the $\mathrm{p}<0.05$ level by the Student-Newman-Keuls test. The symbols ** and n.s. means significant difference at the $\mathrm{p}<0.01$ and non-significant level, respectively, for a given treatment condition among the contrasting genotypes.

For yield parameters, neither 10-panicles weight nor grain per panicle and spikelet sterility showed significant HNT $\times$ genotypes interaction. However, for 1000 -grain weight was verified significant $(\mathrm{P}<0.001)$ interaction 
(Figure 9). Additionally, whereas the HNT decreased grain weight for BRS-Quer, unaltered performance was highlight for N22, indicating its higher stability when compared ones.
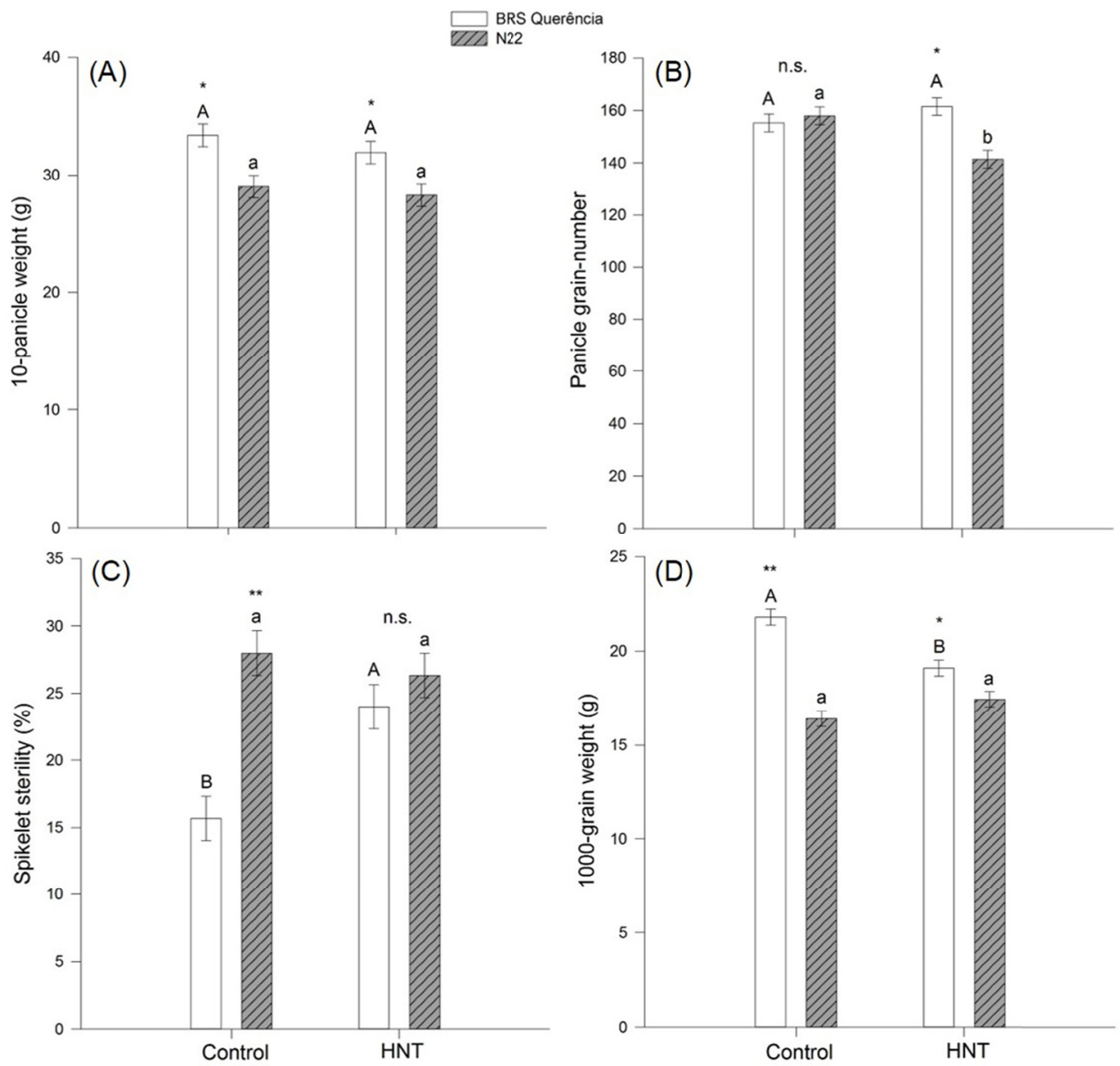

Figure 9. 10-panicle weight (A), panicle grain-number (B), spikelet sterility (C) and 1000-grain weight (D) in rice genotypes submitted to different temperatures regime

Note. For white columns (BRS Querência - BRS-Quer) and cross gray columns (Nagina22 - N22) followed by the same capital letter and the same lowercase letter, respectively, are not significantly different at the $\mathrm{p}<0.05$ level by the Student-Newman-Keuls test. The symbols *,** and n.s. means significant difference at the $\mathrm{p}<0.05$; $\mathrm{p}<0.01$ and non-significant level, respectively, for a given treatment condition among the contrasting genotypes.

\section{Discussion}

In this study, beyond other physiological approaches, PAL enzyme which catalyzes the first step of the phenylpropanoid was monitored on seventh and on twenty-first days after stress imposing in two contrasting rice genotypes for heat stress. Although there were many studies with respect to PAL responses to a variety of environmental conditions, there is scarcity of data for approaches evaluating effects of high night temperature on plant rice physiological and/or biochemical responses. The analysis suggests that PAL is constitutively expressed by N22 across temperature regime and time exposition. In other way, the sensitive genotype (BRS-Quer) increased its level activity in responses to stress, subsequently decreasing their activity on twenty-first day after stress imposing, highlighting a later acclimation response. Different studies have demonstrated that several environmental factors can trigger PAL activity as such nutrient supply, light conditions including UV radiation, attack of microbial pathogens or atmospheric $\mathrm{CO}_{2}$ concentration and temperature oscillation (Kenrick \& Crane, 1997; Huang et al., 2010). However, studies associating PAL activities responses for rice plants under high night temperature conditions not were found in our source, being at least scarce. In this sense, is need consider that secondary metabolism is closely connected to primary metabolism and influenced by substrate rate which can be 
available for secondary biosynthetic routes. Whether it's true, then any environmental factor can trigger activation some pathway signal transduction lead to a response related to photosynthesis, growth and, consequently, primary metabolism could also affect the secondary metabolism (Ibrahim et al., 2012). Thus, occurrence of high night temperature can be considered one of these factors and in a future climate scenarios, the increase in global temperature as result of climate change could lead to changes in plant secondary metabolites biosynthesis altering the source-sink flow and consequently NSC accumulation and remobilization to grain filling; beyond plant capacity to respond to biotic and abiotic stresses could be altered. Based in allocation hypotheses new carbon-nutrient balance and growth differentiation balance are proposed (Herms \& Mattson, 1992) to predict the effects of infra and/or supra-optimal occurrence of environmental factors, where temperature oscillation also could be included.

In this way, results obtained in this study suggest that unaltered PAL activities shown by N22 can contribute maintain unaltered some yield components such as spikelet sterility rate, grain per panicle and 1000-grain weight when submitted to high night temperature. In other way, BRS-Quer genotype which showed an increase of 8\% and a decrease of $12 \%$ for spikelet sterility percentage and 1000-grain weight, respectively also showed the highest PAL activities values on seventh and on twenty-first day after stress imposing.

The endosperm cell of rice contributes for more than $90 \%$ of the grain weight of a caryopsis. In this sense, the size of sink and/or low activity of enzymes involved in the carbohydrates metabolism could contribute to a low grain filling rate depending of their degree of sensibility to HNT. In our report, under optimum HNT the BRS-Quer genotype, which have a bigger panicle when compared to N22, showing a more sink strength with a decrease of $36 \%$ of stem starch concentration from heading to milk stage; in other way, when submitted to HNT its starch levels were unaltered during evaluated period. Results of different studies have indicated that activities of enzymes involved in the breakdown of sucrose in the sink could influence the sink activity and, consequently define the local concentration sucrose-starch rate, as result of unloading of sucrose from phloem (Ranwala $\&$ Miller, 1998; Liang et al., 2001). Besides, there is need to consider that SuSase is a main enzyme involved in the cleavage of sucrose in rice grains; because its importance in this event it have been considered as an important biochemical marker of sink activity (Kato, 1995; Liang et al., 2001; Zhang et al., 2014; You et al., 2016). In other way, AGPase has been also considered as a key enzyme participating in the starch synthesis, and its activity is associated with rate and quantity of starch synthesis (Ahmadi \& Baker, 2001; Yang et al., 2004, 2017). AGPase at the early grain filling stage were decreased as result of supra-optimal temperatures (Ahmed et al., 2015); under other abiotic stress, as such water deficit, SuSase and AGPase had its activities levels influenced. The results suggest that the bigger capacity of N22 to maintain higher soluble sugar levels (fructose, glucose and sucrose) at milk stage can have contributed to their better yield component stability across night temperatures imposed.

The photosynthesis induction curve highlighted that HNT caused small decreases in some photochemical quenching of fluorescence as well as tendency to increases of non-phochemical quenching, affecting more prominently BRS-Quer genotype. Nevertheless, these changes in photosynthesis performance observed only on seventh day of stress cannot explain the great differences found between two genotypes for its yield components as above discussed.

Studies involving the approaches that aim quantify the heat-stress effects on rice physiological performance and their yield components and identification of genetic variability have become increasingly in last decade. However, few studies have concentrate efforts to evaluate rice biochemical/physiological responses under high night temperatures (Chaturvedi et al., 2017) and there are scarcity of information about rice plant responses when are submitted to high night supra-optimal temperatures. Different studies have suggested that the amount of NSC mobilization in the post-heading stem could result from sink strength and environment/management (Yang et al., 2000; Chen \& Wang, 2008; Kim et al., 2011; Morita \& Nakano, 2011; Li et al., 2017; Wada et al., 2017). In other way, NSC level at maturity cannot be attributed to lower mobilization because additional photoassimilate re-accumulation can be result from its semi-perennial characteristics. Besides, accumulation, remobilization and re-accumulation of NSC in stem can be influenced by genotype, environment and genotypes environment interaction. In this sense, in the next step efforts will be concentrating to monitor enzymes activities involved in the phenylpropanoid pathway together with the NSC dynamics from heading until maturity phase in different organs, i.e. leaves, stem and spikelets in development aiming to elucidate these responses and define the more adequate organ and best phase to validate this approach as proxy for rice physiological breeding.

In conclusion, the results indicate that high night temperature imposed from heading to milk stage can leading changes in source-flow-sink related attributes in contrasting genotype beyond modify PAL activity responses, lead to changes in nature of NSC accumulation and translocation. These changes could impact in plant secondary metabolites biosynthesis altering the source-sink flow and consequently NSC accumulation and remobilization 
to grain filling. The data suggest yet that higher translocation capacity shown by N22 can contribute to their lower spikelet sterility rate and higher 1000-grain weight stability across the environments tested. These results suggests that the hypersensitive phenylpropanoid pathway activation shown by sensitive genotype should be taken into account and could serves as a starting point for new efforts aiming establish a biochemical traits as a potential marker in rice physiological breeding for future climate scenarios.

\section{Acknowledgements}

Financial support was provided by CNPq via CHAMADA UNIVERSAL- MCTI/CNPq No 14/2014) and Brazilian Agricultural Research Corporation - EMBRAPA via Macro II Edital.

\section{References}

Ahmadi, A., \& Baker, D. A. (2001). The effect of water stress on the activities of key regulatory enzymes of the sucrose to starch pathway in wheat. Plant Growth Regulation, 35(1), 81-91. https://doi.org/10.1023/ A:1013827600528

Ahmed, N., Tetlow, I. J., Nawaz, S., Iqbal, A., Mubin, M., Nawaz ul Rehman, M. S., ... Maekawa, M. (2015). Effect of high temperature on grain filling period, yield, amylose content and activity of starch biosynthesis enzymes in endosperm of basmati rice. Journal of the Science of Food and Agriculture, 95(11), 2237-2243. https://doi.org/10.1002/jsfa.6941

Bahuguna, R. N., Solis, C. A., Shi, W., \& Jagadish, K. S. (2017). Post-flowering night respiration and altered sink activity account for high night temperature-induced grain yield and quality loss in rice (Oryza sativa L.). Physiologia Plantarum, 159(1), 59-73. https://doi.org/10.1111/ppl.12485

Baker, N. R. (2008). Chlorophyll fluorescence: A probe of photosynthesis in vivo. Annual Review of Plant Biology, 59(1), 89-113. https://doi.org/10.1146/annurev.arplant.59.032607.092759

Becklin, K. M., Anderson, J. T., Gerhart, L. M., Wadgymar, S. M., Wessinger, C. A., \& Ward, J. K. (2016). Examining plant physiological responses to climate change through an evolutionary lens. Plant Physiology, 172(2), 635-649. https://doi.org/10.1104/pp.16.00793

Brito, G. G., Caixeta, E. T., Gallina, A. P., Zambolim, E. M., Zambolim, L., Diola, V., \& Loureiro, M. E. (2010). Inheritance of coffee leaf rust resistance and identification of AFLP markers linked to the resistance gene. Euphytica, 173(2), 255-264. https://doi.org/10.1007/s10681-010-0119-x

Brito, G. G., Fagundes, P. R. R., Teló, G. M., Abreu, A. G., Júnior, A. M. M., Franco, D. F., ... Petrine, J. A. (2016). Impact of supra-optimal temperatures on physiology and yield in rice field. Journal of Agricultural Science, 8(2), 27-37. https://doi.org/10.5539/jas.v8n2p27

Brito, G. G., Sofiatti, V., Lima, M. M. A., Carvalho, L. P., \& Silva-Filho, J. L. (2011). Physiological traits for drought phenotyping in cotton. Acta Scientiarum Agronomy, 33(1), 117-125. https://doi.org/10.4025/ actasciagron.v33i1.9839

Campos, A. D., Ferreira, A. G., Hampe, M. M. V., Antunes, I. F., Brancão, N., Silveira, E. P., ... Osório, V. A. (2003). Induction of chalcone synthase and phenylalanine ammonia-lyase by salicylic acid and Colletotrichum lindemuthianum in common bean. Brazilian Journal of Plant Physiology, 15(3), 129-134. https://doi.org/10.1590/S1677-04202003000300001

Chaturvedi, A. K., Bahuguna, R. N., Shah, D., Pal, M., \& Jagadish, S. V. K. (2017). High temperature stress during flowering and grain filling offsets beneficial impact of elevated $\mathrm{CO}_{2}$ on assimilate partitioning and sink-strength in rice. Scientific Reports, 7(1), 8227. https://doi.org/10.1038/s41598-017-07464-6

Chen, H. J., \& Wang, S. J. (2008). Molecular regulation of sink-source transition in rice leaf sheaths during the heading period. Acta Physiologiae Plantarum, 30(5), 639-649. https://doi.org/10.1007/s11738-008-0160-8

Chow, P. S., \& Landhausser, S. M. (2004). A method for routine measurements of total sugar and starch content in woody plant tissues. Tree Physiology, 24(10), 1129-1136. https://doi.org/10.1093/treephys/24.10.1129

Counce, P. A., Keisling, T. C., \& Mitchell, A. J. (2000). A uniform, objective, and adaptative system for expressing rice development. Crop Science, 40(2), 436-443. https://doi.org/10.2135/cropsci2000.402436x

Dempsey, D. M. A., \& Klessig, D. F. (2017). How does the multifaceted plant hormone salicylic acid combat disease in plants and are similar mechanisms utilized in humans? BMC Biology, 15(1), 23. https://doi.org/10.1186/s12915-017-0364-8 
Diola, V., Brito, G. G., Caixeta, E. T., Maciel-Zambolim, E., Sakiyama, N. S., \& Loureiro, M. E. (2011). High-density genetic mapping for coffee leaf rust resistance. Tree Genetics \& Genomes, 7(6), 1199-1208. https://doi.org/10.1007/s11295-011-0406-2

Diola, V., Brito, G. G., Caixeta, E. T., Pereira, L. F. P., \& Loureiro, M. E. (2013). A new set of differentially expressed signaling genes is early expressed in coffee leaf rust race II incompatible interaction. Functional \& Integrative Genomics, 13(3), 379-389. https://doi.org/10.1007/s10142-013-0330-7

Dixon, R. A., \& Paiva, N. L. (1995). Stress-induced phenylpropanoid metabolism. The Plant Cell, 7(7), 1085-1097. https://doi.org/10.1105/tpc.7.7.1085

Dixon, R. A., Achnine, L., Kota, P., Liu, C. J., Reddy, M. S., \& Wang, L. (2002). The phenylpropanoid pathway and plant defence-a genomics perspective. Molecular Plant Pathology, 3(5), 371-390. https://doi.org/ 10.1046/j.1364-3703.2002.00131.x

Fan, X., Tang, Z., Tan, Y., Zhang, Y., Luo, B., Yang, M., ... Xu, G. (2016). Overexpression of a pH-sensitive nitrate transporter in rice increases crop yields. Proceedings of the National Academy of Sciences, 113(26), 7118-7123. https://doi.org/10.1073/pnas.1525184113

Godfray, H. C. J., Beddington, J. R., Crute, I. R., Haddad, L., Lawrence, D., Muir, J. F., ... Toulmin, C. (2010). Food security: The challenge of feeding 9 billion people. Science, 327(5967), 812-818. https://doi.org/ 10.1126/science. 1185383

Guimarães, C. M., Stone, L. F., Brito, G. G., \& Heuert, J. (2017). Evaluation of water-stress tolerance of Acala SJ 2 and Auburn 2 cotton cultivars in a phenotyping platform. Revista Ambiente \& Água, 12(4), 629-642. https://doi.org/10.4136/ambi-agua.2105

Herms, D. A., \& Mattson, W. J. (1992). The dilemma of plants: To grow or defend. The Quarterly Review of Biology, 67(3), 283-335. https://doi.org/10.1086/417659

Huang, J., Gu, M., Lai, Z., Fan, B., Shi, K., Zhou, Y. H., ... Chen, Z. (2010). Functional analysis of the Arabidopsis PAL gene family in plant growth, development, and response to environmental stress. Plant Physiology, 153(4), 1526-1538. https://doi.org/10.1104/pp.110.157370

Hyodo, H., \& Yang, S. F. (1971). Ethylene enhanced synthesis of phenylalanine ammonia-lyase in pea seedlings. Plant Physiology, 47(6), 765-770. https://doi.org/10.1104/pp.47.6.765

Hyodo, H., Kuroda, H., \& Yang, S. F. (1978). Induction of phenylalanine ammonia-lyase and increase in phenolics in lettuce leaves in relation to the development of russet spotting caused by ethylene. Plant Physiology, 62(1), 31-35. https://doi.org/10.1104/pp.62.1.31

Ibrahim, M. H., Jaafar, H. Z. E., Karimi, E., \& Ghasemzadeh, A. (2012). Primary, secondary metabolites, photosynthetic capacity and antioxidant activity of the malaysian herb kacip fatimah (Labisia pumila benth) exposed to potassium fertilization under greenhouse conditions. International Journal of Molecular Sciences, 13(11), 15321-15342. https://doi.org/10.3390/ijms131115321

Intergovernmental Panel on Climate Change (IPCC). (2013). The Physical Science Basis. In T. F. Stocker, D. Qin, G. K. Plattner, M. Tignor, S. K. Allen, J. Boschung, ... P. M. Midgley (Eds.), Contribution of Working Group I to the Fifth Assessment Report of the Intergovernmental Panel on Climate Change (p. 1535). Cambridge University Press, Cambridge, United Kingdom and New York, NY, USA.

Kato, T. (1995). Change of sucrose synthase activity in developing endosperm of rice cultivars. Crop Science, 35(3), 827-831. https://doi.org/10.2135/cropsci1995.0011183X003500030032x

Kato, Y., Collard, B. C., Septiningsih, E. M., \& Ismail, A. M. (2014). Physiological analyses of traits associated with tolerance of long-term partial submergence in rice. AoB Plants, 6. https://doi.org/10.1093/ aobpla/plu058

Kenrick, P., \& Crane, P. R. (1997). The origin and early evolution of plants on land. Nature, 389(6646), 33-39. https://doi.org/10.1038/37918

Kim, J., Shon, J., Lee, C. K., Yang, W., Yoon, Y., Yang, W. H., ... Lee, B. W. (2011). Relationship between grain filling duration and leaf senescence of temperate rice under high temperature. Field Crops Research, 122(3), 207-213. https://doi.org/10.1016/j.fcr.2011.03.014

Li, G., Pan, J., Cui, K., Yuan, M., Hu, Q., Wang, W., ... Peng, S. (2017). Limitation of unloading in the developing grains is a possible cause responsible for low stem non-structural carbohydrate translocation and 
poor grain yield formation in rice through verification of recombinant inbred lines. Frontiers in Plant Science, 8, 1369. https://doi.org/10.3389/fpls.2017.01369

Liang, J., Zhang, J., \& Cao, X. (2001). Grain sink strength may be related to the poor grain filling of indica-japonica rice (Oryza sativa) hybrids. Physiologia Plantarum, 112(4), 470-477. https://doi.org/ 10.1034/j.1399-3054.2001.1120403.x

Lowry, O. H., Rosebrough, N. J., Farr, A. L., \& Randall, R. J. (1951). Protein measurement with the folin phenol reagent. The Journal of Biology Chemistry, 193(1), 265-275.

MacDonald, M. J., \& D’Cunha, G. B. (2007). A modern view of phenylalanine ammonia lyase. Biochemistry and Cell Biology, 85(3), 273-282. https://doi.org/10.1139/o07-018

Morita, S., \& Nakano, H. (2011). Nonstructural carbohydrate content in the stem at full heading contributes to high performance of ripening in heat-tolerant rice cultivar Nikomaru. Crop Science, 51(2), 818-828. https://doi.org/10.2135/cropsci2010.06.0373

Pan, J., Cui, K., Wei, D., Huang, J., Xiang, J., \& Nie, L. (2011). Relationships of non-structural carbohydrates accumulation and translocation with yield formation in rice recombinant inbred lines under two nitrogen levels. Physiologia Plantarum, 141(4), 321-331. https://doi.org/10.1111/j.1399-3054.2010.01441.x

Pascual, M. B., El-Azaz, J., de la Torre, F. N., Cañas, R. A., Avila, C., \& Cánovas, F. M. (2016). Biosynthesis and metabolic fate of phenylalanine in conifers. Frontiers in Plant Science, 7, 1030. https://doi.org/10.3389/ fpls.2016.01030

Ranwala, A. P., \& Miller, W. B. (1998). Sucrose-cleaving enzymes and carbohydrate pools in Lilium longiflorum floral organs. Physiology Plantarum, 103(4), 541-550. https://doi.org/10.1034/j.1399-3054. 1998.1030413.x

Saint Pierre, C., Trethowan, R., \& Reynolds, M. (2010). Stem solidness and its relationship to water-soluble carbohydrates: Association with wheat yield under water deficit. Functional Plant Biology, 37(2), 166-174. https://doi.org/https://doi.org/10.1071/FP09174

Shimono, H., Okada, M., Yamakawa, Y., Nakamura, H., Kobayashi, K., \& Hasegawa, T. (2009). Genotypic variation in rice yield enhancement by elevated $\mathrm{CO}_{2}$ relates to growth before heading, and not to maturity group. Journal of Experimental Botany, 60(2), 523-532. https://doi.org/10.1093/jxb/ern288

SigmaPlot 13.0 - Systat Software San Jose C. Sigmaplot - exact graphs and data analysis. 13.0 ed.

Streeter, J. G., \& Strimbu, C. E. (1998). Simultaneous extraction and derivatization of carbohydrates from green plant tissues for analysis by gas-liquid chromatography. Anal Biochemestry, 259(2), $253-257$. https://doi.org/10.1006/abio.1998.2675

Tian, Z., Niu, Y. L., Sun, L. X., Li, C. S., Liu, C. J., \& Fan, D. L. (2015). China's rice field greenhouse gas emission under climate change based on dndc model simulation. The Journal of Applied Ecology, 26(3), 793-799.

Wada, H., Masumoto-Kubo, C., Tsutsumi, K., Nonami, H., Tanaka, F., Okada, H., ... Morita, S. (2017). Turgor-responsive starch phosphorylation in Oryza sativa stems: A primary event of starch degradation associated with grain-filling ability. PLoS One, 12(7), e0181272. https://doi.org/10.1371/journal. pone. 0181272

Weber, R. L., Wiebke-Strohm, B., Bredemeier, C., Margis-Pinheiro, M., Brito, G. G., Rechenmacher, C., ... Bodanese-Zanettini, M. H. (2014). Expression of an osmotin-like protein from Solanum nigrum confers drought tolerance in transgenic soybean. BMC Plant Biology, 14, 343. https://doi.org/10.1186/s12870014-0343-y

Yang, J., Zhang, J., Huang, Z., Zhu, Q., \& Wang, L. (2000). Remobilization of carbon reserves is improved by controlled soil-drying during grain filling of wheat. Crop Science, 40(6), 1645-1655. https://doi.org/ $10.2135 /$ cropsci2000.4061645x

Yang, J., Zhang, J., Wang, Z., Xu, G., \& Zhu, Q. (2004). Activities of key enzymes in sucrose-to-starch conversion in wheat grains subjected to water deficit during grain filling. Plant Physiology, 135(3), 1621. https://doi.org/10.1104/pp.104.041038

Yang, J., Zhang, J., Wang, Z., Zhu, Q., \& Wang, W. (2001). Remobilization of carbon reserves in response to water deficit during grain filling of rice. Field Crops Research, 71(1), 47-55. https://doi.org/10.1016/ S0378-4290(01)00147-2 
Yang, Y., Gao, T., Xu, M., Dong, J., Li, H., Wang, P., ... Wang, Y. (2017). Functional analysis of a wheat AGPase plastidial small subunit with a truncated transit peptide. Molecules, 22(3). https://doi.org/10.3390/ molecules 22030386

Yoshida, S. (1981). Fundamentals of rice crop science. Los Baños: IRRI.

You, C., Chen, L., He, H., Wu, L., Wang, S., Ding, Y., \& Ma, C. (2017). iTRAQ-based proteome profile analysis of superior and inferior spikelets at early grain filling stage in japonica rice. BMC Plant Biology, 17(1), 100. https://doi.org/10.1186/s12870-017-1050-2

You, C., Zhu, H., Xu, B., Huang, W., Wang, S., Ding, Y., ... Tang, S. (2016). Effect of removing superior spikelets on grain filling of inferior spikelets in rice. Frontiers in Plant Science, 7, 1161. https://doi.org/10.3389/fpls.2016.01161

Zhang, W. J., Wu, L. M., Ding, Y. F., Weng, F., Wu, X. R., Li, G. H., ... Wang, S. H. (2016). Top-dressing nitrogen fertilizer rate contributes to decrease culm physical strength by reducing structural carbohydrate content in japonica rice. Journal of Integrative Agriculture, 15(5), 992-1004. https://doi.org/10.1016/ S2095-3119(15)61166-2

Zhang, Z., Zhao, H., Tang, J., Li, Z., Li, Z., Chen, D., \& Lin, W. (2014). A proteomic study on molecular mechanism of poor grain-filling of rice (Oryza sativa L.) inferior spikelets. PLoS One, 9(2), e89140. https://doi.org/10.1371/journal.pone.0089140

Zhu, C., Zhu, J., Cao, J., Jiang, Q., Liu, G., \& Ziska, L. H. (2014). Biochemical and molecular characteristics of leaf photosynthesis and relative seed yield of two contrasting rice cultivars in response to elevated $\mathrm{CO}_{2}$. Journal of Experimental Botany, 65(20), 6049-6056. https://doi.org/10.1093/jxb/eru344

\section{Copyrights}

Copyright for this article is retained by the author(s), with first publication rights granted to the journal.

This is an open-access article distributed under the terms and conditions of the Creative Commons Attribution license (http://creativecommons.org/licenses/by/4.0/). 